\title{
AN APPLICATION OF ANN FOR MODELING AND OPTIMISATION OF PROCESS PARAMETERS OF MANUFACTURING PROCESS: A REVIEW
}

\author{
Nitin Kumar Rathi \\ Department of Mechanical Engineering \\ Acropolis Inst. of Tech. \& Research \\ Indore, M.P., India
}

\author{
Nisha Rathi \\ Department of Computer Science \& Engineering \\ Acropolis Inst. of Tech. \& Research, \\ Indore, M.P., India
}

\begin{abstract}
In this day and age, the technologies of fifth generation i.e. Artificial Neural Networks (ANN) and Machine Learning are extensively applied for modelling as well as optimizing the performance and effectiveness i.e. Optimization of process parameters of the manufacturing processes. Previously the choice of suitable process parameters was a hard and tedious task. Rule-based schemes, proficiency, understanding and familiarity of domain of particular technologists are mandatory to be known for the selection of suitable parameters of the manufacturing processes. At this time, there is a speedy change in the nature of manufacturing processes. It is now more complicated. As of varying customer's demand and reduced product life cycle, continuous changes are taking place, thus, manufacturing technologies those are easily and readily adjustable to such changes are in great demand. With the perspective of demand of readily adaptable manufacturing technologies, Artificial Neural Networks is an influential tool. This modern technology enables us to discover complex, non-linear patterns in data, and then on the basis of experimental data these patterns are converted into models. Next, they are applied to fine-tuning process parameters. This paper is a review on the appliance of the ANN and its incorporation with various optimisation methods i.e. Hybrid methods for the optimization of the manufacturing process.
\end{abstract}

Keywords - Process Parameter optimisation, Modelling, Machine Learning, Artificial Neural Network, Artificial Intelligence in manufacturing

\section{INTRODUCTION}

Currently, businesses and industries endeavor to accomplish high manufacturing and production speed, high quality of products, dimensional accurateness and precision, surface finish, cost reduction and reduced environmental impact. The competitive accomplishment of manufacturing corporations relies on product and process quality. The objective of quality engineering is to discover optimum values of various design parameters to ensure the consistent performance of the product / process in actual use.

Product/process optimization is a common problem in many industries. Optimization is any act, process, or methodology that makes something - such as a design, system, or decision - as good, functional, or effective as possible or in other words maximisation of profit function and minimisation of cost function. The appropriate and prompt selection of process parameters in manufacturing processes plays a significant role to ensure the quality of the product, to reduce the machining cost and to increase the productivity of the process. The selection of efficient machining parameters is of great concern in manufacturing industries, where economy of machining operations plays a key role in the competitive market.

Artificial Neural network (ANN) model is an efficient and accurate tool for modelling/simulating manufacturing processes. Artificial neural networks (ANNs) are one of the most powerful computer modelling techniques, based on statistical approach, currently being used in many fields of engineering for modelling complex relationships which are difficult to describe with physical models. Many researchers have dealt with the modelling and optimization of process parameters in manufacturing processes using artificial neural networks (ANNs) and machine learning methods. Artificial neural networks (ANN) are biologically inspired computer programs designed to simulate the way in which the human brain processes information. ANNs gather their knowledge by detecting the patterns and relationships in data and learn (or are trained) through experience, not from programming. Therefore, the implementation of ANN is hugely beneficial in industrial applications in order to save cost and material resources.

This paper is an important study of ANN(s) in manufacturing applications that has been published on different journals. In the engineering literature the papers vary significantly based on network architectures definition, results validation, training algorithms, error measures and so on.

The rest of the paper is organized as follows: Brief description about Artificial Neural Network(ANN) is covered in section 


\section{International Journal of Engineering Applied Sciences and Technology, 2020 \\ Vol. 4, Issue 12, ISSN No. 2455-2143, Pages 127-134 \\ Published Online April 2020 in IJEAST (http://www.ijeast.com)}

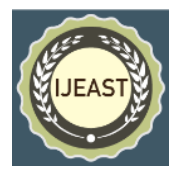

II. Section III reviews the existing papers on various manufacturing process parameters optimization using ANN. Concluding remarks are given in section IV.

\section{ARTIFICIAL NEURAL NETWORK}

For the modelling of manufacturing process there exist a number of options but for a variety of reasons, one particular choice has been mostly examined and explored in the literature i.e. artificial neural networks (ANNs).

ANNs has been extracted from artificial intelligence. Subsequent to the neural structure of the brain, the simple electronic devices called Artificial Neural Networks (ANNs) are modelled. ANNs are skilled in learning from experiments and performing non-linear mappings. Artificial neurons or nodes are the processing elements of neural networks. Investigation of functioning of neuron assists us to build the ANNs. An ANN may be observed as a black box containing hierarchical groups of neurons (i.e. processing elements) that produce outputs for specific inputs.

\section{A. ANN Structure -}

Brief description of the various components in an ANN Structure:

Inputs: They are the action of assembling data from the appropriate sources.

Weights: The intent of this function is to control the effect of the inputs on the neuron. An ANN keeps its information above its links. The relation between the inputs and outputs are optimized by constant variations in weights over the links.

Summation function: It calculates the net input readings from the processing elements.

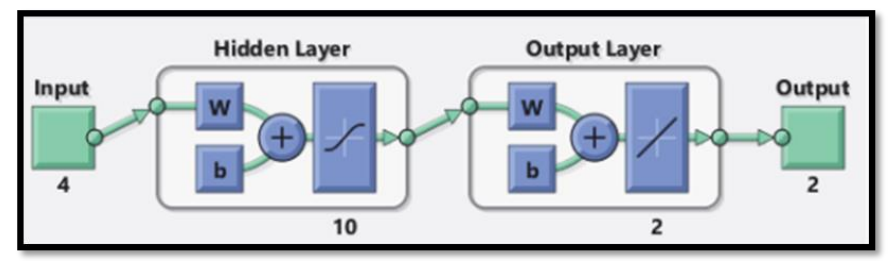

Fig. 1. Artificial Neural Network Structure

Transfer (activation) function: By accepting the net input provided by the summation function, the activation function is aimed to determine the output of the neuron. There are several transfer functions exists and the choice of the transfer and summation function is based on the nature of the problem. Transfer functions include algebraic equations of linear or nonlinear form. A network will be able to store nonlinear relationships between the input and the output through nonlinear transfer function. Sigmoid function is the commonly used function as it is self-limiting and has a simple derivative. In Sigmoid function the output cannot grow infinitely huge or little.
Outputs: This identifies the results of the transfer function and gives it ahead to the relevant processing element or to the outside of the network.

There are various categories of neural networks based on their structure, activation functions and training algorithms. Each neural network could be functional merely in a few specific processes as it has its individual input-output characteristics. The complete method may be evaluated in terms of the inputs, weights, the summation function and the activation function.

\section{$B$. Layers in ANN -}

The three types of layers considered in ANN are the input layer, the output layer, and the hidden layer as shown in fig 2. On the input layer, each neuron is assigned to an attribute in data. The output is comprised of the scaled value of the corresponding attribute. The intermediate layer between the input and output layers is the hidden layers that usually numbering one or two.

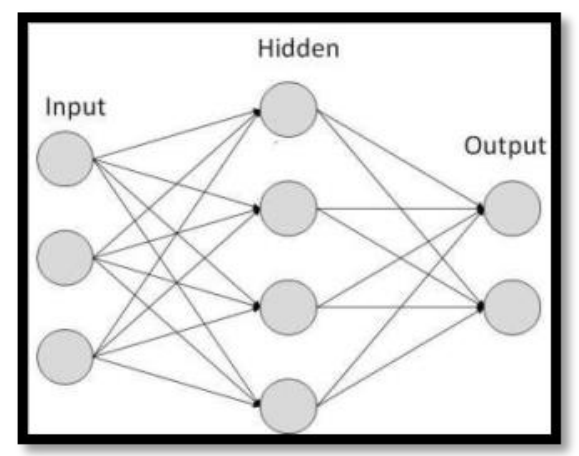

Fig. 2. Layers in Artificial Neural Network

Input layer: The set of input units that accepts information about the instance to be propagated all the way through the network comprises Input layer of Artificial Neural Network.

Hidden layer: A set of hidden units take input from the input layer. The hidden units collectively form hidden layer. The set of input units forms the input to every hidden unit and leads to a weighted sum as the output. The number of hidden units is usually smaller than the number of input units.

Output layer: In neural network, the output layer collects and transmits the information according in way it has been designed to give. The pattern obtainable by the output layer can be directly sent back to the input layer. The neural network performs by the direct relation of number of neurons in output layer.

\section{ANN Model -}

Multilayer perceptron (MLP) is the most frequently used ANN model, Rao (2010). As this model requires a desired output in order to learn, therefore, such a type of neural network is identified as a supervised network. It works with the aim to create a model that perfectly maps the input to the output by 


\section{International Journal of Engineering Applied Sciences and Technology, 2020 \\ Vol. 4, Issue 12, ISSN No. 2455-2143, Pages 127-134 \\ Published Online April 2020 in IJEAST (http://www.ijeast.com)}

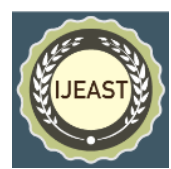

means of historical data and subsequently generate the output when the required output is unknown.

A popular learning method of the multi-layered neural network is the back-propagation. The MLP and several other neural networks gain knowledge and learn using this backpropagation algorithm. In this method, the forward path computing of the multi-layered neural network is carrying out with each layer fully connected to the next layer. With back propagation, the input data is repetitively offered to the neural network. With each appearance, the output of the neural network is compared to the required output and an error is calculated. This computed error is then fed back (back propagated) to the neural network and weights are adjusted such that the error reduces with each iteration and ultimately the neural model gets nearer to generate the required output. This overall process is called "training."

In general, there exist three varieties of learning approaches:

- Supervised Learning: The trainer may tell the network what it should learn.

- Unsupervised Learning: the network learns without any intervention of the trainer.

- Reinforcement Learning: the trainer may point out whether or not the output is accurate without mentioning what the network should learn.

In supervised learning the required outputs occur in this set while in other two cases they are not found in it. Generally, neural networks are tuned or trained so that a particular input generates a particular target output. Using experimental patterns, the training and test data are prepared. The comparison of an output and the target leads to adjustment of network until the network matches the target. Usually, for training of network numerous input-target pairs are used in the supervised learning. For an optimum topology and weights, a neural network is trained with a number of data and tested with other set of data. Once trained, the neural networks can be used for prediction.

\section{A BRIEF REVIEW OF THE WORK ALREADY DONE IN THE FIELD \& NOTEWORTHY CONTRIBUTIONS}

Related to the areas of parameter optimization and parameter setting for different kinds of manufacturing processes, there exist a vast research literature. Researchers working on the related domain indicated that the method of Artificial Neural Networks is flexible and has a capability to be efficiently integrated with other optimisation techniques (Hybrid methods). The integration of ANN as a modeling tool and optimization algorithms are beneficial in determining optimum process environment for the manufacturing processes.

Analytical modeling of the process is unfeasible and complicated because of the complication of the process and diversity of parameters and their interactive effects on one another. Some significant artificial intelligence applications to particular production processes are picked and described here. For Injection moulding process, In this research work, Navin Kumar et al. (2018), the researchers has considered sink mark or shrinkage during the process as productivity estimate with the aim to reduce it to the minimum. The selection of an optimal process environment (optimal parameter setting) fulfilled the response requirements. Artificial neural network and regression analysis are used to obtain the setting data and the objective function. Further, Genetic Algorithm technique is used for optimization of objective function. The model is proven to be effective as percentage shrinkage mark improved using optimized injection moulding process parameters in contrast with preceding literature. In this paper, Iniesta et al. (2013), the author presented a mixture of artificial neural networks and artificial bee colony algorithm. They made use of feed forward neural network to obtain a mathematical association between the process parameters and the optimization goal of minimizing warpage of plastic products. For generating the optimal solution, artificial bee colony algorithm is used to find the optimal set of process parameters values. Melt temperature, mold temperature, packing pressure, packing time, and cooling time are considered as the design variables. Results revealed the proposed strategy is capable to support engineers in determining the optimal process parameters and attaining competitive advantages in terms of quality and costs. In this research work, Meiabadia et al. (2013), author utilized Artificial Neural Network (ANN) for modeling the process. Process conditions data is essential for modeling the process by the neural network. After the step of modeling, the resultant model was united with the Genetic Algorithm (GA). The injection molding goals were turned into fitness function and based on that the optimized conditions were acquired. The idea of this research was to obtain the process parameters that ensure the accurate part weight, less process cycle time, and injection pressure. Results revealed in the literature confirmed that the strategy is capable to support engineers in determining optimal process parameters setting and achieving competitive advantages of product quality and costs.

For Abrasive water jet machining process, In this research, Reddy et al. (2018), an approach of multi-objective has been attempted for the excellent combination of process parameters by modeling AWJM process using ANN. It provided a set of optimal process parameters to AWJ machining process, and demonstrated a development with an improved productivity. For modeling, a wide set of trail experiments were considered with a wide variety of machining parameters, subsequently, for validating also. The proposed model was competent to predict optimized responses.

For different welding processes, In this paper, Sreeraj et al. (2013), for getting the optimum dilution in stainless steel cladding of low carbon structural steel plates using Gas Metal 


\section{International Journal of Engineering Applied Sciences and Technology, 2020 \\ Vol. 4, Issue 12, ISSN No. 2455-2143, Pages 127-134 \\ Published Online April 2020 in IJEAST (http://www.ijeast.com)}

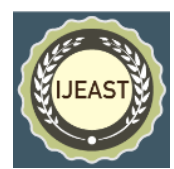

Arc Welding (GMAW), the author provided an experimental study to predict various input process parameters (welding current, welding speed, gun angle, contact tip to work distance and pinch). In this research, based on central composite rotatable design with full replication technique, experiments were conducted. The multiple regression method was used for developing the mathematical models. The developed models have been checked for sufficiency and significance. Artificial Neural Network (ANN) was used for predicting the parameters and the percentage of error was calculated between predicted and actual values. Particle swarm optimization (PSO) algorithm was used for the optimization of parameters. In this paper, Katherasan et al.(2014), the simulation of weld bead geometry in FCAW process using artificial neural networks (ANN) and optimization of process parameters using particle swarm optimization (PSO) algorithm was addressed by researchers. The input process variables taken were wire feed rate, voltage, welding speed and torch angle each having 5 levels. Bead on the plate weldments were made based on the statistical design of experiments by Taguchi $\mathrm{L}_{25}$ orthogonal array. For establishing a relationship between the input and output parameters, the investigational results were fed to the ANN algorithm. Further, the outputs were then embedded into the PSO algorithm which optimizes the process parameters subjected to the objectives. The objectives of the research were maximization of depth of penetration, minimization of bead width and minimization of reinforcement as the process output characteristics. The authors in this work, K. Kamal Babu et al. (2018), carried out parameter optimization of FSW of cryorolled AA2219 alloy to obtain defect free weld joint with maximum weld strength. They used artificial neural network (ANN) to model the relationship between the input parameters and the mechanical and corrosion properties (output) of the weld joints. Genetic algorithm (GA) was used to determine the optimal FSW parameters. The feasible parameter was considered to weld and confirmed the capability of the parameter to produce better weld joint than the $\mathrm{L}_{9}$ orthogonal array parameters. The weld, subjected to the confirmation test, was looked into by means of metallurgical, mechanical, and corrosion testing.

For Milling Process, In this paper, Pohokar et al. (2014) machining parameters, cutting speed, feed, depth of cut, and a geometric parameter rake angle were taken into consideration for optimization. For predicting the results theoretically neural networks were used. To authenticate the results experimentally subsequent experiments are then carried out on a CNC milling. The calculated results matched $90 \%$ including the residuals. Thus, the authors demonstrated that the neural network is used for optimization of geometric and machining parameters. In this effort, Chaskar et al. (2017), the researchers studied non-conventional optimization technique, Artificial Neural Network and Back propagation algorithm and they used these approaches for the optimization of machining parameters in CNC milling operations (i.e. Speed and feed rate). The author used an objective function based on maximum profit in milling operation and developed optimization procedures based on the above-mentioned techniques. On successful implementation, they observed significant improvement in the performance. The authors in this work, Yazdi et al. (2010), selected optimal machining parameters (i.e. spindle speed, depth of cut and feed rate) and examined for face milling operations. Then they investigated the effects of selected parameters on process variables (i.e., surface roughness and material removal rate) using Response Surface Methodology (RSM) and artificial neural networks for the minimization of the surface roughness and for maximization of the material removal rate. Best machining parameters were carried out by means of RSM and compared to the experimental results. The obtained results indicated that the RSM and ANN methods have suitable capability for milling process modeling and optimization.

For turning process, In this learning, Ilhan Asiltürk et al. (2011), the surface roughness was calculated for the period of turning at different cutting parameters for example speed, feed, and depth of cut. To boost the confidence limit and reliability of the experimental data, full factorial experimental design was applied. For modelling the surface roughness of AISI 1040 steel, artificial neural networks (ANN) and multiple regression approaches were used by the author. Multiple regression and neural network-based models are evaluated with statistical methods. It is observed that the proposed models were competent to predict the surface roughness. The ANN model approximated the surface roughness with high accurateness compared to the multiple regression models.

For drilling process, This paper, Nakhjavani et al. (2006) is a study of laser percussion drilling optimization by combining the neural network method with the genetic algorithm. At the initial level, with the purpose of optimizing every single output parameter (response) of the process despite of their effect on each other (single criterion optimization), the author obtained the optimum input parameters of the process. Subsequently, optimum input parameters were obtained in order to optimize the effect of all output parameters in a multicriteria manner. For the development of an experimental model of the process according to the experimental results, artificial neural network (ANN) method was used. Using genetic algorithm (GA), the optimum input parameters (peak power, pulse width, pulse frequency, number of pulses, assist gas pressure, and focal plane position) were specified. The output parameters were comprised of the hole entrance diameter, circularity of hole entrance and hole exit, and hole taper. The tests were conducted on mild steel EN3 sheets. Taking into account the accuracy of the optimum numerical results and the high capability of the neural network in modeling, this method is found to be reliable and accurate and verifies the qualitative results in the earlier studies. 
For various EDM Process, In this work, Somashekhar et al.(2010), the author presented the development of modeling and optimization for micro-electric discharge machining $(\mu-$ EDM) process. To analyze the material removal of $\mu$-EDM for establishing the parameter optimization model, they used artificial neural network (ANN) model. For the optimization of the number of neurons and number of hidden layers to predict a better material removal rate, the author trained a feed forward neural network with back propagation algorithm. On comparison of experimental and network model results for the performance considered, it is examined that the proposed model is within the restrictions of the permissible error. Next, they employed genetic algorithms (GAs) to determine the optimum process parameters for any desired output value of machining characteristics. This compliant neural network model was found to be very effective in estimating the MRR and was enhanced using optimized machining parameters. This study, Ugrasena et al. (2014), summarizes the development of model and its application to optimize WEDM machining parameters by means of the Taguchi's technique which is based on the robust design. Taguchi's L'16 orthogonal array-based experimentation has been carried out under diverse cutting conditions of pulse-on, pulse-off, current, and bed speed. Voltage and flush rate were kept constant among different process parameters. For each experiment three responses that is accuracy, surface roughness, and volumetric material removal rate were taken into account. Based on this investigation, process parameters are optimized. ANOVA is performed to decide the comparative magnitude of each factor on the objective function. Using artificial neural network, estimation and comparison of responses were conducted.

For Fused Deposition Modeling process, The researchers, Sood et al. (2010) used the experimental data for efficient training and testing of artificial neural network (ANN) model that finely maps the association between the input process control factors and output responses. Bayesian regularization is used for selection of optimum network architecture. Bayesian regularization has an ability to fix number of network parameters irrespective of network size. Author used Levenberg-Marquardt algorithm for the training of ANN model. The resulting network had good generalization ability that removes the possibility of over fitting. Lastly, the combination of ANN network with bacterial-foraging optimization algorithm (BFOA) is used to propose theoretical combination of parameter settings, and thus improve mechanical strength related responses of fused deposition modeling (FDM) processed parts. In this article, Yadav et al. (2020), authors talked about the effects of material density, infill density and extrusion temperature on tensile strength of Acrylonitrile Butadiene Styrene (ABS), Polyethylene Terephthalate Glycol (PETG), and Multimaterial test pieces. Merging 5of 50\% of ABS and 50\% of PETG layer by layer has been done for fabrication of Multi- material in FDM 3D Printing. As per the ASTM standard, a 30 test pieces were prepared. For training and optimization purposes, the authors used artificial neural network (ANN) and genetic algorithm-artificial neural network (GA-ANN) hybrid tool in MATLAB-16.0. In conclusion, it was quoted by the authors that GA-ANN has maximized the tensile strength up to $4.54 \%$ and it has been confirmed by authors experimentally. In this study, Mohamed et al. (2016), the influence of multi-level manufacturing parameters on the temperature-dependent dynamic mechanical properties of FDM processed parts was investigated using IV-optimality response surface methodology (RSM) and multilayer feedforward neural networks (MFNNs). The process parameters considered for optimization and investigation are slice thickness, raster to raster air gap, deposition angle, part print direction, bead width, and number of perimeters. Storage compliance and loss compliance were considered as response variables. The effect of each process parameter was investigated using developed regression models and multiple regression analysis. The comparison between the experimental values and the predicted values by IV-Optimal RSM and MFNN was conducted for each experimental run and results indicate that the MFNN provides better predictions than IVOptimal RSM.

For Gear Hobbing Process, In this work, Cao et al. (2016), presents a hybrid improved back propagation neural network/differential evolution (IBPNN/DE) approach to do a continuous optimization decision making of process parameters in high-speed gear hobbing. Gear hobbing effect evaluation model is first structured to assess the machining effect. The optimization population of the process parameters, which is the input of the DE module, is generated by the IBPNN module. Using the DE algorithm, the best of best process parameters is obtained during the course of working.

For Boring Process, In this paper, Rao et al. (2016), statistical models were developed to investigate effect of cutting parameters on surface roughness and root mean square of work piece vibration in boring of stainless steel. A mixed level design of experiments was prepared with process variables of nose radius, cutting speed and feed rate. According to design of experiments, eighteen experiments were conducted on AISI 316 stainless steel with PVD coated carbide tools. Surface roughness, tool wear and vibration of work piece were measured in each experiment. A laser Doppler vibrometer was used to measure vibration of work piece in the form of acousto optic emission signals. These signals were processed and transformed in to different frequency zones using a fast Fourier transformer. Analysis of variance was used to identify significant cutting parameters on surface roughness and root mean square of work piece vibration. Predictive models like response surface methodology, artificial neural network and support vector machine were used to predict the surface roughness and root mean square of work piece vibration. 


\section{International Journal of Engineering Applied Sciences and Technology, 2020 \\ Vol. 4, Issue 12, ISSN No. 2455-2143, Pages 127-134 \\ Published Online April 2020 in IJEAST (http://www.ijeast.com)}

Cutting parameters were optimized for minimum surface roughness and root mean square of work piece vibration using a multi response optimization technique.

\section{CONCLUSION}

Artificial neural network is an influential data modeling tool that is capable to capture and characterize the complex inputoutput relationships. Process parameters are usually considered as autonomous variables. The common prospect is to consider models that present lesser errors in prediction as compared to other approaches. Thus, the optimized process parameters are observed which is better in performance. In comparison with other modeling techniques, the construction of excellent ANN models is a difficult and challenging task. The ability of neural networks in representing linear and nonlinear relationships and the ability to learn these relationships directly from the data being modeled depicts the supremacy and benefits neural networks. Conventional linear models insufficient and fails in modeling data containing non-linear characteristics. ANN is an eye-catching substitute for several researchers to model a variety of manufacturing processes because it has ability of learning non-linear relationship in manufacturing operations without going deep into the mathematical intricacy, prior supposition on the functional forms of the relationship between inputs, in-process parameters and outputs. This is the trade-off for the betterquality computing capability of an artificial neural network. In this survey, complete information on applications of ANN and machine learning methods for modeling of different manufacturing process and their process parameters optimisation is concisely presented and summarized in table 1(Appendix A).

This review article is intended to offer readers a better understanding of the ANN method and it's up to date study in the field of production process optimisation. This article also provides broad insight into the active research carried out on process parameter optimization of the various manufacturing process by using combination of diverse tools and ANN.

\section{REFERENCE}

[1] R. Venkata Rao (2010),Advanced Modeling and Optimization of Manufacturing Processes, International Research and Development,Springer Series in Advanced Manufacturing

[2] Navin Kumar and Mayur Thombre (2018), Optimization of Injection Moulding Process Parameters for Reducing Shrinkage by Using Genetic Algorithm Technique, IJARIIE-ISSN(O)-2395-4396, Vol-4 Issue-2

[3] Alejandro Alvarado Iniesta, Jorge L. García Alcaraz, Manuel Iván Rodríguez Borbón (2013), Optimization of injection molding process parameters by a hybrid of artificial neural network and artificial bee colony algorithm, Article in Revista Facultad de Ingeniería
[4] Mohammad Saleh Meiabadia, Abbas Vafaeesefatb, Fatemeh Sharific (2013), Optimization of Plastic Injection Molding Process by Combination of Artificial Neural Network and Genetic Algorithm, Journal of Optimization in Industrial Engineering, 13(pp.49-54)

[5] Srinath Reddy N, Dinesh Tirumalaa, Rajyalakshmi Gajjelaa and Raja Dasb (2018),ANN and RSM approach for modelling and multi objective optimization of abrasive water jet machining process, Decision Science Letters, 7(pp.535-548)

[6] P Sreeraj,T Kannan and Subhashis Maji (2013), Simulation And Parameter Optimization Of GMAW Process Using Neural Networks And Particle Swarm Optimization Algorithm, Int. J. Mech. Eng. \& Rob. Res. , Vol. 2, No. 1

[7] D. Katherasan, Jiju V. Elias, P. Sathiya \& A. Noorul Haq(2014), Simulation and parameter optimization of flux cored arc welding using artificial neural network and particle swarm optimization algorithm, Journal of Intelligent Manufacturing,volume 25,(pp.67-76)

[8] K. Kamal Babu, K. Panneerselvam, P. Sathiya, A. Noorul Haq, S. Sundarrajan, P. Mastanaiah \& C. V. Srinivasa Murthy (2018),Parameter optimization of friction stir welding of cryorolled AA2219 alloy using artificial neural network modeling with genetic algorithm", The International Journal of Advanced Manufacturing Technology, volume 94, (pp.3117-3129)

[9] Nilesh Pohokar and Lalit Bhuyar (2014),Neural Networks Based Approach for Machining and Geometric Parameters optimization of a CNC End Milling, International Journal of Innovative Research in Science,Engineering and Technology, Vol. 3, Issue 2

[10] P.R.Chaskar,A.S.Lad,J.K.Mane,A.Sangre,S.Kirkire (2017),Optimization of CNC Milling Parameters Using Artificial Neural Network, Imperial Journal of Interdisciplinary Research (IJIR), Vol-3, Issue-2

[11] M.R. Soleymani Yazdi and A. Khorram (2010), Modeling and Optimization of Milling Process by using RSM and ANN Methods, IACSIT International Journal of Engineering and Technology, Vol.2, No.5

[12] Ilhan Asiltürk and Mehmet Cunkas (2011),Modeling and prediction of surface roughness in turning operations using artificial neural network and multiple regression method, Expert Systems with Applications, Volume 38, Issue 5,(pp.5826-5832)

[13] O.B.Nakhjavani and M. Ghoreishi (2006), Multi Criteria Optimization of Laser Percussion Drilling Process Using Artificial Neural Network Model Combined with Genetic Algorithm,Materials and Manufacturing Processes, Volume 21, Issue 1

[14] K. P. Somashekhar, N. Ramachandran \& Jose Mathew (2010), Optimization of Material Removal Rate in MicroEDM Using Artificial Neural Network and Genetic 


\section{International Journal of Engineering Applied Sciences and Technology, 2020 \\ Vol. 4, Issue 12, ISSN No. 2455-2143, Pages 127-134 \\ Published Online April 2020 in IJEAST (http://www.ijeast.com)}

Algorithms, Materials $\quad$ and $\quad$ Manufacturing
Processes, Volume 25, Issue 6

5] G.Ugrasena , H.V.Ravindrab, G.V.Naveen Prakashc, R.Keshavamurthyd (2014),Process optimization and Estimation of Machining performances using Artificial Neural Network in Wire EDM, 3rd International Conference on Materials Processing and Characterisation (ICMPC)

[16] Anoop Kumar Sood, R. K. Ohdar, S. S. Mahapatra (2010),A Hybrid ANN-BFOA Approach for Optimization of FDM Process Parameters, International Conference on Swarm,Evolutionary, and Memetic Computing,SEMCCO: Swarm,Evolutionary,andMemeti cComputing,(pp.396-403)

[17] Dinesh Yadav, Deepak Chhabra, Ramesh Kumar Garg, Akash Ahlawat (2020), Optimization of FDM 3D printing process parameters for multi-material using artificial neural network, Materials Today: Proceedings, Volume 21, Part 3, (pp1583-1591)

[18] Omar Ahmed Mohamed, Syed Hasan Masood and Jahar Lal Bhowmik (2016), "Analytical Modelling and Optimization of the Temperature-Dependent Dynamic Mechanical Properties of Fused Deposition Fabricated Parts Made of PC-ABS", Materials , 9, 895
[19] W. D. Cao, C. P. Yan, L. Ding \& Y. F. Ma (2016),A continuous optimization decision making of process parameters in high- speed gear hobbing using IBPNN/DE algorithm, The International Journal of Advanced ManufacturingTechnology,volume 85,(pp.2657-2667)

[20] K. Venkata Rao, P. B. G. S. N. Murthy(2016),Modeling and optimization of tool vibration and surface roughness in boring of steel using RSM, ANN and SVM, Article in Journal of Intelligent Manufacturing

[21] Dorina Weichert, Patrick Link, Anke Stoll, Stefan R uping Steffen Ihlenfeldt, Stefan Wrobel (2019), A review of machine learning for the optimization of production Processes, The International Journal of Advanced Manufacturing Technology,104(pp.1889-1902)

Appendix-A

Table -1 Summary of Application of ANN for manufacturing process optimisation

\begin{tabular}{|c|c|c|c|}
\hline Reference & Broad Area & Optimization Problem Details & Technique used \\
\hline Kumar et al. & \multirow{3}{*}{$\begin{array}{l}\text { Injection } \\
\text { Moulding } \\
\text { Process }\end{array}$} & $\begin{array}{l}\text { Optimization of Injection Moulding } \\
\text { Process Parameters for Reducing } \\
\text { Shrinkage }\end{array}$ & $\begin{array}{l}\text { Artificial Neural Network (ANN), } \\
\text { Regression Analysis and Genetic } \\
\text { Algorithm (RAGA) }\end{array}$ \\
\hline Alvarado et al. & & $\begin{array}{l}\text { Optimization of Injection Molding Process } \\
\text { Parameters for minimize warpage of } \\
\text { plastic products }\end{array}$ & $\begin{array}{l}\text { Artificial Neural Network (ANN), } \\
\text { artificial bee colony algorithm } \\
(\mathrm{ABCO})\end{array}$ \\
\hline Meiabadia et al. & & $\begin{array}{l}\text { Optimization of Plastic Injection Molding } \\
\text { Process Parameters for product quality and } \\
\text { costs }\end{array}$ & $\begin{array}{l}\text { Artificial Neural Network (ANN), } \\
\text { Genetic Algorithm (GA) }\end{array}$ \\
\hline Reddy et al. & $\begin{array}{l}\text { Abrasive water } \\
\text { jet machining } \\
\text { process }\end{array}$ & $\begin{array}{l}\text { Modelling and multi objective } \\
\text { optimization of abrasive water jet } \\
\text { machining process with an improved } \\
\text { productivity }\end{array}$ & $\begin{array}{l}\text { Artificial Neural Network (ANN), } \\
\text { RSM (Response Surface } \\
\text { Methodology) }\end{array}$ \\
\hline Sreeraj et al. & \multirow[t]{3}{*}{ Welding process } & $\begin{array}{l}\text { Simulation and parameter optimization of } \\
\text { GMAW process }\end{array}$ & $\begin{array}{l}\text { RSM, Artificial Neural Network } \\
\text { (ANN), Particle Swarm Optimization } \\
\text { (PSO) }\end{array}$ \\
\hline Katherasan et al. & & $\begin{array}{l}\text { Optimization of Flux Cored Arc Welding } \\
\text { process }\end{array}$ & $\begin{array}{l}\text { Artificial Neural Network (ANN), } \\
\text { Particle Swarm Optimization (PSO) }\end{array}$ \\
\hline Kamal Babu et al. & & $\begin{array}{l}\text { Optimization of parameters for friction } \\
\text { stirs welding of cryorolled AA } 2219 \text { alloy }\end{array}$ & $\begin{array}{l}\text { Artificial Neural Network (ANN), } \\
\text { Genetic Algorithm (GA) }\end{array}$ \\
\hline Pohokar et al. & Milling & $\begin{array}{l}\text { Optimization of Machining and Geometric } \\
\text { Parameters of a CNC End Milling }\end{array}$ & Artificial Neural Network (ANN) \\
\hline
\end{tabular}


International Journal of Engineering Applied Sciences and Technology, 2020

Vol. 4, Issue 12, ISSN No. 2455-2143, Pages 127-134

Published Online April 2020 in IJEAST (http://www.ijeast.com)

\begin{tabular}{|c|c|c|c|}
\hline Chaskar et al. & & Optimization of CNC Milling Parameters & $\begin{array}{l}\text { Artificial Neural Network (ANN), } \\
\text { Back propagation algorithm }\end{array}$ \\
\hline Yazdi et al. & & $\begin{array}{l}\text { Modeling and Optimization of Milling } \\
\text { Process for minimization of the surface } \\
\text { roughness and for maximization of the } \\
\text { material removal rate }\end{array}$ & $\begin{array}{l}\text { Artificial Neural Network (ANN), } \\
\text { RSM (Response Surface } \\
\text { Methodology) }\end{array}$ \\
\hline Ilhan Asiltürket al. & Turning Process & $\begin{array}{l}\text { Modeling and prediction of surface } \\
\text { roughness in turning operations }\end{array}$ & $\begin{array}{l}\text { Artificial Neural Network (ANN), } \\
\text { Multiple Regression Method }\end{array}$ \\
\hline Nakhjavani et al. & Drilling Process & $\begin{array}{l}\text { Optimization of Laser Percussion Drilling } \\
\text { Process }\end{array}$ & $\begin{array}{l}\text { Artificial Neural Network (ANN), } \\
\text { Genetic Algorithm (GA) }\end{array}$ \\
\hline Somashekhar et al. & \multirow[t]{2}{*}{$\begin{array}{l}\text { Electro } \\
\text { Discharge } \\
\text { Machine }\end{array}$} & $\begin{array}{l}\text { Optimization of Material Removal Rate in } \\
\text { Micro-EDM }\end{array}$ & $\begin{array}{l}\text { Artificial Neural Network (ANN), } \\
\text { Feed Forward Neural Network with } \\
\text { back propagation algorithm, Genetic } \\
\text { Algorithm (GA) }\end{array}$ \\
\hline Ugrasena et al. & & $\begin{array}{l}\text { Process optimization and estimation of } \\
\text { machining performances in wire EDM }\end{array}$ & $\begin{array}{l}\text { Artificial Neural Network (ANN), } \\
\text { Taguchi’s technique, ANOVA }\end{array}$ \\
\hline Sood et al. & \multirow[t]{3}{*}{$\begin{array}{l}\text { Fused } \\
\text { Deposition } \\
\text { Modeling }\end{array}$} & $\begin{array}{l}\text { Optimization of fused deposition modeling } \\
\text { (FDM) Process Parameters to improve } \\
\text { mechanical strength }\end{array}$ & $\begin{array}{l}\text { Artificial Neural Network (ANN), } \\
\text { Bacterial-Foraging optimization } \\
\text { algorithm (BFOA) }\end{array}$ \\
\hline Yadav et al. & & $\begin{array}{l}\text { Optimization of FDM 3D printing process } \\
\text { parameters for multi-material tensile } \\
\text { strength }\end{array}$ & $\begin{array}{l}\text { ANN, genetic algorithm-artificial } \\
\text { neural network (GA-ANN) hybrid } \\
\text { tool }\end{array}$ \\
\hline $\begin{array}{l}\text { Omar Ahmed } \\
\text { Mohamed et al. }\end{array}$ & & $\begin{array}{l}\text { parameters effects on the temperature- } \\
\text { dependent dynamic mechanical properties } \\
\text { of FDM processed parts was investigated }\end{array}$ & $\begin{array}{l}\text { Response surface methodology } \\
\text { (RSM) and multilayer feed-forward } \\
\text { neural networks (MFNNs). }\end{array}$ \\
\hline Cao et al. & $\begin{array}{l}\text { Hobbing } \\
\text { process }\end{array}$ & $\begin{array}{l}\text { Continuous optimization decision making } \\
\text { of process parameters in high-speed gear } \\
\text { hobbing. }\end{array}$ & IBPNN/DE Approach \\
\hline Rao et al. & Boring process & $\begin{array}{l}\text { Cutting parameters were optimized for } \\
\text { minimum surface roughness and root } \\
\text { mean square of work piece vibration } \\
\text { using a multi response optimization } \\
\text { technique }\end{array}$ & $\begin{array}{l}\text { Response surface methodology, } \\
\text { Artificial Neural Network }\end{array}$ \\
\hline
\end{tabular}

